\title{
Hydroxychloroquine drastically reduces immune activation in HIV-infected, antiretroviral therapy-treated immunologic nonresponders
}

\author{
Stefania Piconi, ${ }^{1}$ Serena Parisotto, ${ }^{2}$ Giuliano Rizzardini, ${ }^{1}$ Simone Passerini, ${ }^{1}$ Roberta Terzi, ${ }^{1}$ Barbara Argenteri, ${ }^{1}$ \\ Paola Meraviglia, ${ }^{1}$ Amedeo Capetti, ${ }^{1}$ Mara Biasin, ${ }^{2}$ Daria Trabattoni, ${ }^{2}$ and Mario Clerici 2,3 \\ ${ }^{1}$ I Divisione Malattie Infettive, H.L. Sacco, Milan, Italy; ${ }^{2}$ Cattedra Immunologia, Università degli Studi di Milano, Milan, Italy; and ${ }^{3}$ Fondazione Don Gnocchi \\ ONLUS, Milan, Italy
}

\begin{abstract}
Despite optimal suppression of HIV replication, restoration of $\mathrm{CD}^{+} \mathrm{T}$ cells is not always achieved in antiretroviral therapytreated individuals. Defective CD4 recovery in immunologic nonresponders is possibly associated with TLR-mediated immune activation driven by alterations of gut permeability. Hydroxychloroquine (HCQ) reduces endosomal TLR signaling; thus, we verified whether $H C Q$ could dampen immune activation and be associated with an increase in CD4 ${ }^{+} \mathrm{T}$ cells. To this end, we enrolled in a prospective study 20 HIV-infected immunologic nonresponders (CD4 count $<200$ cells $/ \mathrm{mL}$ or
\end{abstract}

CD4 increase $<5 \%$ in the last 12 months) who received $400 \mathrm{mg} /$ day $\mathrm{HCQ}$ for 6 months. HCQ had a notable impact on immune activation as shown by significant modifications of the following parameters: (1) reduced plasma lipopolysaccharide; (2) decreased TLR4-expressing CD14 ${ }^{+}$cells, TLR4-mediated signal transduction, and mRNA synthesis; (3) reduced percentages of activated $\mathrm{CD}^{+}$ $\left(\mathrm{CD}^{+} / \mathrm{Ki67}^{+}\right)$and $\mathrm{CD} 14^{+}\left(\mathrm{CD} 14^{+} / \mathrm{CD} 69^{+}\right)$ cells; (4) increased T-regulatory cells (Tregs), naive Tregs, and TLR4expressing Tregs; (5) augmented plasmacytoid dendritic cells and reduced IFN $\alpha$ - secreting plasmacytoid dendritic cells; and (6) reduced IL-6 and TNF $\alpha$ production. HCQ-induced immune modulation was associated with increased percentages of circulating $\mathrm{CD4}^{+} \mathrm{T}$ cells and was mostly retained 2 months after therapy interruption. $\mathrm{HCQ}$ reduces lipopolysaccharide/TLR-mediated immune activation; this compound could be a useful immunomodulant in HIV-infected patients. This study is registered at EutraCT as 2009-012499-28 with study number HLS01/ 2009-1-16-03-2009. (Blood. 2011;118(12): 3263-3272)

\section{Introduction}

The antimalarial drug hydroxychloroquine (HCQ) is endowed with immune modulatory effects including the reduction of inflammatory cytokine production ${ }^{1,2}$ and of IgG levels and a downmodulation of natural killer cell activity; these properties have warranted its use in autoimmune conditions including lupus erythematosus, Sjögren syndrome, and rheumatoid arthritis. ${ }^{3-6}$ In vitro data, ${ }^{7}$ as well as results obtained in a murine model, ${ }^{8}$ have shown that HCQ also modulates the intracellular TLR pathway as it reduces TLR9 and TLR4 expression and the CpG DNA- and lipopolysaccharide (LPS)-mediated activation of NF- $\mathrm{B}$ and AP-1. In addition to these effects, HCQ is characterized by antiviral properties as witnessed by the ability of this compound to prevent the entry of influenza and adenoviruses into target cells, ${ }^{9}$ to be an obstacle to retroviral infection in murine models, ${ }^{10}$ and to impede HIV-1 replication in vitro. ${ }^{11,12}$ Of note, chloroquine decreases Tat-mediated transactivation of HIV-1 LTR in vitro as well, thereby decreasing HIV-1 production, ${ }^{13}$ and alters the immunogenic properties of gp $120 .{ }^{14}$

On the basis of these findings, the use of HCQ has been evaluated in HIV infection. Results showed that decreases in viral load, IL-6, and serum IgG titers, ${ }^{15-17}$ as well as a reduction in immune activation and a decrease in $\mathrm{CD} 38^{+} \mathrm{CD} 8^{+} \mathrm{T}$ cells and $\mathrm{Ki} 67$ memory CD4 ${ }^{+}$T cells ${ }^{18,19}$ can be observed in HIV-infected patients receiving HCQ. The effect of this compound on these immune parameters is important, given that immune activation is believed to play a key role in HIV pathogenesis. ${ }^{19,20}$ This suggestion stems from several observations. Thus, the massive destruction of $\mathrm{CD}^{+}$ $\mathrm{T}$ cells in the gastrointestinal mucosa observed in the initial phases of the infection would provoke severe mucosal alterations, allowing the translocation of products generated by the microbiota in the systemic circulation. As a consequence, plasma concentrations of LPS would increase, resulting in TLR-mediated immune activation. $^{21-23}$ The triggering of TLR4 by LPS, together with the stimulation of TLR3 and TLR9 by viral RNA- or DNA-containing unmethylated $\mathrm{CpG}$ dinucleotides, would therefore be the ultimate culprit of the immune activation observed in HIV infection. ${ }^{22}$ Of note, HIV-induced mucosal alterations are suggested to persist over the whole course of disease, as testified to by the observation that abnormal LPS plasma concentrations and a degree of activation involving $\mathrm{CD}^{+}$and $\mathrm{CD}^{+} \mathrm{T}$ lymphocytes are maintained even in the presence of antiretroviral therapy (ART)-induced suppression of HIV replication. ${ }^{20}$

Quantitative CD4 ${ }^{+}$T-cell defects are observed in a percentage of HIV-infected ART-treated patients (immunologic nonresponders [INRs]). The pathogenesis of this phenomenon is still unclear, and several immune alterations were shown to be present in INRs including: (1) a reduction in $\mathrm{CD}^{+}{ }^{+} \mathrm{T}$-memory cell proliferation at the central level, ${ }^{23}$ (2) an increased susceptibility of T lymphocytes to apoptosis, ${ }^{24}$ (3) higher levels of LPS ${ }^{25}$ and immune activation, ${ }^{26}$ and (4) residual viral replication. ${ }^{27-29}$ These observations led to therapeutic approaches based either on therapy intensification ${ }^{30,31}$
Submitted January 7, 2011; accepted March 15, 2011. Prepublished online as Blood First Edition paper, May 16, 2011; DOI 10.1182/blood-2011-01-329060.

The publication costs of this article were defrayed in part by page charge payment. Therefore, and solely to indicate this fact, this article is hereby marked "advertisement" in accordance with 18 USC section 1734.

(C) 2011 by The American Society of Hematology 
or immunomodulation ${ }^{32}$ that, nevertheless, did not result in any significant effect.

We recently reported that lack of proper $\mathrm{CD}^{+}{ }^{+} \mathrm{T}$-cell recovery in HIV-treated patients correlates with LPS-associated and TLR-mediated immune activation. ${ }^{33}$ On the basis of these observations and the ability of HCQ to downregulate TLR-mediated activation, ${ }^{18}$ we evaluated whether this compound would have an effect on immune activation and $\mathrm{CD}^{+}{ }^{+} \mathrm{T}$-cell numbers in HIVinfected INRs.

\section{Methods}

\section{Study population}

Twenty ART-treated HIV-infected patients with an absolute CD4 count $<200$ cells/ $\mu \mathrm{L}$ during the last 12 months of therapy and with suppressed viremia ( $<37$ HIV RNA copies/mL) were consecutively enrolled in the study. All patients were treated with combined antiretroviral therapy according to the current guidelines (a nonnucleoside reverse transcriptase inhibitor plus a protease inhibitor or a nucleoside reverse transcriptase inhibitor plus a nonnucleoside reverse transcriptase inhibitor). Exclusion criteria included glucose-6-phosphate dehydrogenase deficit, pregnancy, breast feeding, acute infectious diseases, or CD4 T-cell count increase $>5 \%$ in the last year. All patients received HCQ (400 mg/day) for 6 months. Virologic and immunologic parameters were evaluated at baseline, at the end of treatment, and at 2 months after HCQ suspension. All individuals were enrolled by Infectious Diseases Units at Luigi Sacco Hospital, Milan, Italy, which approved this study; written informed consent was obtained before enrollment in accordance with the Declaration of Helsinki.

\section{Blood sample collection and PBMC separation}

Whole blood was collected by venipuncture in Vacutainer tubes containing EDTA (BD Biosciences). Plasma was stored and PBMCs were separated on lymphocyte separation medium (Cedarlane Laboratories Limited) and washed twice in PBS (PBI). The number of viable leukocytes was determined by trypan blue exclusion.

\section{Stimulation of PBMCs}

PBMCs were incubated for 18 hours in the presence or absence of a pool of env + gag peptides (HIV, $2.5 \mu \mathrm{M})^{34}$ kindly provided by Dr Renato Longhi (CNR Institute, Milan, Italy). For cytokine analyses, $1 \mu \mathrm{g} / \mathrm{mL}$ brefeldin A (Sigma-Aldrich) was added to the cell cultures 6 hours before cell analyses to block protein secretion.

\section{Immunophenotypic analysis}

Lymphocyte subsets were evaluated using $50 \mu \mathrm{L}$ of EDTA-treated peripheral blood incubated for 10 minutes at room temperature with fluorochromelabeled mAbs (anti-CD4, -CD8, and -CD14, PECy7; anti-CD14 and -CD25, PECy5; anti-CD69, allophycocyanine [APC]; anti-HLA-DR, -CD38, and -TLR4, PE; and anti-CD8, -CD16, -CD45RO, and -TLR2, FITC). Erythrocyte lysis and fixation of stained cells were performed at the end of the incubation period using the IMMUNOPREP EPICS Kit and Q-prep Workstation (Coulter Electronics). Cytometric analyses were performed on 200000 events using a FC500 flow cytometer (Beckman-Coulter). Green fluorescence from FITC (FL1) was collected through a 525-nm band pass filter, red fluorescence from PE (FL2) was collected through a 575-nm band pass filter, orange fluorescence from phycoerythrin-Texas red (ECD; FL3) was collected through a $620-\mathrm{nm}$ band pass filter, deep-red fluorescence from PECy5 (FL4) was collected through a 670-nm band pass filter, red fluorescence from APC (FL4) was collected through a 650-nm band pass filter, and far-red fluorescence from PECy7 (FL5) was collected through a 770-nm band pass filter. Linear amplifiers were used for forward and side scatters and logarithmic amplifiers for FL1, FL2, FL3, FL4, and FL5. Samples were first run using isotype controls. Flow data were analyzed by first gating on the lymphocyte and monocyte population as defined by forward and sidelight scatters. CD4-, CD8-, or CD14-positive cells against side scatter were then selected and used to evaluate the percentage of positive cells for the marker analyzed. Data were analyzed using Kaluza 1.1 software (Beckman Coulter).

\section{Ki-67 evaluation}

PBMCs were washed in PBS and stained for CD4 PECy7 mAb for 15 minutes at room temperature in the dark before being fixed in $1 \%$ paraformaldehyde (PFA; Sigma-Aldrich) for 15 minutes at $4{ }^{\circ} \mathrm{C}$ and washed. Cells were then resuspended in $0.5 \%$ saponin (Sigma-Aldrich) and stained for Ki-67 or mouse FITC-coupled IgG1 (isotype control). After a 45-minute incubation at $4{ }^{\circ} \mathrm{C}$ in the dark, cells were washed and fixed in $1 \%$ PFA.

Flow data were analyzed by first gating on the lymphocyte population as defined by forward and sidelight scatters and on $\mathrm{CD} 4^{+}$cells. Results were expressed as the percentage of $\mathrm{CD} 4{ }^{+} \mathrm{Ki}-67^{+}$cells on $\mathrm{CD} 4{ }^{+}$population.

\section{Identification of plasmacytoid dendritic cells and IFN $\alpha$ production}

Analyses were performed both in basal and stimulated conditions as described above under "Stimulation of PBMCs." PBMCs were washed in PBS, incubated with anti-CD123 PECy7, lineage ${ }^{-}$PECy5 (LIN ${ }^{-}$: antiCD3, -CD14, -CD16, -CD19, and -CD56), and anti-HLA DRII PE for 15 minutes, fixed with $1 \%$ PFA, incubated for 15 minutes at $4^{\circ} \mathrm{C}$ in the dark, washed with PBS, and permeabilized with $0.5 \%$ saponin. Anti-IFN $\alpha$ mAbs were then added before a 45 -minute incubation at $4{ }^{\circ} \mathrm{C}$ in the dark. Cells were then fixed with $1 \%$ PFA, and plasmacytoid dendritic cells (pDCs) were identified by flow cytometry $\left(\mathrm{CD} 123{ }^{+} \mathrm{HLADR}^{+} \mathrm{LIN}^{-}\right)$; IFN $\alpha$ expression on these cells was evaluated.

\section{TLR4, TLR7, and TLR8 expression on stimulated monocytes}

PBMCs were stimulated for 18 hours with LPS (TLR4 agonist; SigmaAldrich) or single-stranded RNA (ssRNA; TLR7 and TLR8 agonist; InvivoGen). For TLR4, PBMCs were washed with PBS, incubated with anti-CD14 PC5 and anti-TLR4 PE (eBioscience) mAbs for 15 minutes in the dark and were subsequently fixed with 1\% PFA. For TLR7 and TLR8, PBMCs were washed with PBS and incubated with anti-CD14 PC5 for 15 minutes in the dark at room temperature. After a second washing, cells were permeabilized with $0.5 \%$ saponin and incubated with anti-TLR8 PE (Imgenex) and anti-TLR7 FITC (R\&D Systems) for 45 minutes at $4^{\circ} \mathrm{C}$. At the end of this incubation, PBMCs were washed with PBS and fixed with $1 \%$ PFA.

\section{Plasma LPS concentration}

LPS concentration was measured in plasma with the LAL Chromogenic Endpoint Assay (Hycult Biotechnology). Samples, prepared according to the manufacturer's instructions, were plated in a 96-well plate, followed by LAL reagent. After a 45-minute incubation at room temperature, absorbance was measured $(405 \mathrm{~nm})$ with a spectrophotometer. LPS concentration is expressed in endotoxin units per milliliter and was calculated relative to a standard curve.

\section{Plasma TNF $\alpha$ and IL- 6 concentration}

Proinflammatory cytokines were evaluated in plasma using commercial ELISA kits (R\&D Systems) following the manufacturer's instructions. The plasma concentration of each protein was calculated relative to a standard curve.

\section{Identification of T-regulatory lymphocytes and of TLR-expressing T-regulatory lymphocytes}

PBMCs were incubated with anti-CD4 PC7, anti-CD25 ECD, and antiPD-1 PE for 15 minutes at room temperature. ${ }^{35}$ The intracellular staining of PD1 and FoxP3 was performed according to the manufacturer's instructions (eBioscience). To detect TLR-expressing T-regulatory cells (Tregs), PBMCs were stained with CD4 PC7, CD25 ECD, TLR4 PE, and TLR2 FITC mAbs. 
Intracellular staining of FoxP3 was performed according to the manufacturer's instructions (eBioscience).

\section{Intracellular cytokine concentration}

Antigen-stimulated PBMCs were stained for CD4 or CD14 expression. After a 15-minute incubation at room temperature in the dark, cells were fixed in $1 \%$ PFA (Sigma-Aldrich), incubated for 15 minutes at $4^{\circ} \mathrm{C}$, and permeabilized with $0.5 \%$ saponin (Sigma-Aldrich). TNF $\alpha$ PE, TNF $\alpha$ FITC, and IL- $6 \mathrm{mAbs}$ were then added; after a 45 -minute incubation at $4{ }^{\circ} \mathrm{C}$ in the dark, cells were washed and fixed in 1\% PFA (Sigma-Aldrich).

\section{mAbs}

The following mAbs were used: anti-CD123 (mouse IgG1 isotype) PECy7 (BioLegend); anti-CD4 (mouse IgG1 isotype), anti-CD8 (mouse IgG1 isotype), and anti-CD14 (mouse IgG2a isotype) PECy7; anti-CD3 (mouse $\mathrm{IgG1}$ isotype), anti-CD14 (mouse IgG2a isotype), anti-CD16 (mouse IgG1 isotype), anti-CD19 (mouse $\mathrm{IgG1}$ isotype), anti-CD25 (mouse IgG1 isotype), and anti-CD56 (mouse IgG1 isotype) all coupled to PECy5; anti-CD25 (mouse IgG2a isotype) coupled to ECD; anti-HLADR (mouse $\mathrm{IgG1}$ isotype) and anti-CD38 (mouse $\mathrm{IgG1}$ isotype) coupled to $\mathrm{PE}$; anti-CD8 (mouse IgG1 isotype), anti-CD14 (mouse IgG2a isotype), antiCD16 (mouse IgG1 isotype), and anti-CD45RO (mouse IgG2a isotype) coupled to FITC (Beckman-Coulter); anti-TLR4 PE (mouse IgG2a isotype), anti-PD1 PE (mouse IgG1 isotype), and anti-TLR2 FITC (mouse IgG2a isotype); anti-CD69 APC (mouse IgG1 isotype), anti-TLR2 APC (mouse IgG2a isotype), and anti-TLR4 FITC (mouse IgG2a isotype; eBioscience); and recombinant protein annexin V PE (Bender MedSystems). The intracellular staining detection mAbs used were anti-Foxp3 (rat IgG2a isotype) PECy5, anti-PD1 FITC (mouse IgG1 isotype), anti-IL-6 APC (rat IgG1 isotype; BioLegend), anti-human IFNa FITC (mouse IgG1 isotype; PBL), anti-human Ki67 FITC (mouse IgG1 isotype; BD Biosciences); anti-TNF $\alpha$ PE (mouse IgG1 isotype; Beckman Coulter), anti-TNF $\alpha$ FITC (rat IgG1 isotype; Caltag Laboratories), anti-TLR7 FITC (mouse IgG2a isotype; R\&D Systems); and anti-TLR8 PE (mouse IgG1 isotype; Imgenex).

\section{TLR signaling pathway}

On the basis of previously published data, ${ }^{36} 2.5 \times 10^{5}$ freshly isolated PBMCs were incubated for 3 hours with medium alone, LPS $(2 \mu \mathrm{g} / \mathrm{mL})$, or ssRNA40 $(2.5 \mu \mathrm{g} / \mathrm{mL})$. mRNA was extracted from PBMCs by using the acid guanidinium thiocyanate-phenol-chloroform method, dissolved in RNase-free water, and purified from genomic DNA with RNase-free DNase (RQ1 DNase, Promega). One milligram of RNA was reverse-transcribed into first-strand cDNA in a $20-\mu \mathrm{L}$ final volume containing $1 \mu \mathrm{M}$ random hexanucleotide primers, $1 \mu \mathrm{M}$ oligo(dT), and $200 \mathrm{U}$ of Moloney murine leukemia virus reverse transcriptase (Clontech). TLR signaling pathways were analyzed in a PCR array including a set of optimized real-time PCR primer assays on 96-well plates (SABiosciences Corporation) using a SYBR Green PCR mix (Finnzymes). This approach allows the monitoring of mRNA expression of 84 genes related to TLR pathway activation plus 5 housekeeping genes. Controls were also included on each array for genomic DNA contamination, RNA quality, and general PCR performance.

\section{Statistical analyses}

Data were analyzed according to standard statistical tests; $t$ tests were performed to compare patients during treatment. Procedures were based on parametric analyses. The rank-transformed variables were analyzed if distributions were not normal. Statistical analysis was performed using the SPSS statistical package (SPSS Inc).

\section{Results}

\section{Study population}

The clinical and demographic characterization of the patients enrolled in the study is presented in Table 1. HCQ was well
Table 1. Clinical and epidemiologic characteristics of HCQ-treated patients

\begin{tabular}{|c|c|}
\hline Parameter & $\begin{array}{l}\text { HCQ patients } \\
\quad(n=20)^{\star}\end{array}$ \\
\hline Age, y & $49.78 \pm 2.92(28-68)$ \\
\hline Sex (male/female) & $14 / 6$ \\
\hline HIV infection & $5.33 \pm 1.38(1-15)$ \\
\hline Duration of ART, y & $4.43 \pm 1.22(1-15)$ \\
\hline \multicolumn{2}{|l|}{ Viral load, copies HIV RNA/mL* } \\
\hline Baseline & $<37$ \\
\hline $6 \mathrm{mo}$ of $\mathrm{HCQ}$ & $<37$ \\
\hline 2 mo after $\mathrm{HCQ}$ interruption & $<37$ \\
\hline \multicolumn{2}{|l|}{ Coinfections, n (\%) } \\
\hline HBV & $1 / 20(5)$ \\
\hline $\mathrm{HCV}$ & $4 / 20(20)$ \\
\hline $\mathrm{CD}^{+}{ }^{+} \mathrm{T}$-cell count nadir, cells $/ \mathrm{mm}^{3}$ & $54.57 \pm 11.43(6-112)$ \\
\hline $\mathrm{CD}^{+}{ }^{+} \mathrm{T}$ cells, $\%$ & $10.68 \pm 1.07(3.8-18.2)$ \\
\hline CD4+ T-cell counts, cells $/ \mathrm{mm}^{3}$ & $143.70 \pm 13.19(6-200)$ \\
\hline \multicolumn{2}{|c|}{ Total lymphocyte count, mean $\pm \mathrm{SE}$, cells $/ \mathrm{mm}^{3^{*}}$} \\
\hline Baseline & $1403.33 \pm 171.07$ \\
\hline $6 \mathrm{mo}$ of $\mathrm{HCQ}$ & $1338.33 \pm 145.25$ \\
\hline 2 mo after HCQ interruption & $1304.45 \pm 149.65$ \\
\hline \multicolumn{2}{|l|}{ ART treatment, $\mathrm{n}$} \\
\hline $\mathrm{PI}$ & 10 \\
\hline NNRTI & 7 \\
\hline Other & 3 \\
\hline
\end{tabular}

Data are presented as mean \pm SE (range) except where noted.

HBV indicates hepatitis B virus; HCV, hepatitis C virus; NNRTI, nonnucleoside reverse transcriptase inhibitor; and $\mathrm{PI}$, protease inhibitor

${ }^{*}$ No significant differences were detected.

tolerated in all patients with the exception of one individual who reported a maculopapular exanthema after 10 days of treatment. This individual was excluded from the final analyses. HIV viremia was undetectable throughout the study period.

\section{$\mathrm{CD4}^{+} \mathrm{T}$ cells}

The percentage of $\mathrm{CD} 4^{+} \mathrm{T}$ cells was significantly augmented after 6 months of HCQ treatment $(P<.001$; Figure 1A) without changes in total lymphocytes counts (Table 1). This increase was retained 2 months after HCQ suspension $(P=.001)$. A similar trend was observed in $\mathrm{CD}^{+} \mathrm{T}$-cell counts, even if changes did not reach statistical significance (Figure 1B).

\section{Subsets of activated immune cells: $\mathrm{CD} 4^{+}$and $\mathrm{CD} 8^{+} \mathrm{T}$ cells and CD14+ monocytes}

Immune activation results in the detection in peripheral blood of increased quantities of subsets of immune cells expressing particular proteins. To evaluate a possible immunomodulatory effect of HCQ on this immune activation, we analyzed such subsets in all the individuals enrolled in the study.

$\mathrm{CD} 4{ }^{+}$T-cell activation was evaluated in unstimulated cells and on HIV-specific stimulation. The percentage of Ki67-expressing $\mathrm{CD}^{+} \mathrm{T}$ cells (activated $\mathrm{T}$ cells) was significantly reduced after 6 months of HCQ in both unstimulated and in stimulated condition (unstimulated, $P=.005$; env + gag, $P=.003$; Figure $1 C$ ). This effect was retained 2 months after HCQ interruption (unstimulated, $P=.024$; env + gag, $P=.044)$.

The percentage of HLADRII-, CD69-, and CD38/CD45ROexpressing $\mathrm{CD}^{+} \mathrm{T}$ cells decreased as well, albeit not significantly, after 6 months of HCQ treatment. A different pattern was seen when these populations were analyzed 2 months after HCQ interruption. Thus, (1) $\mathrm{CD}^{+} / \mathrm{DRII}^{+}$cells were significantly reduced both in comparison with baseline and with month $6(P=.013$ 

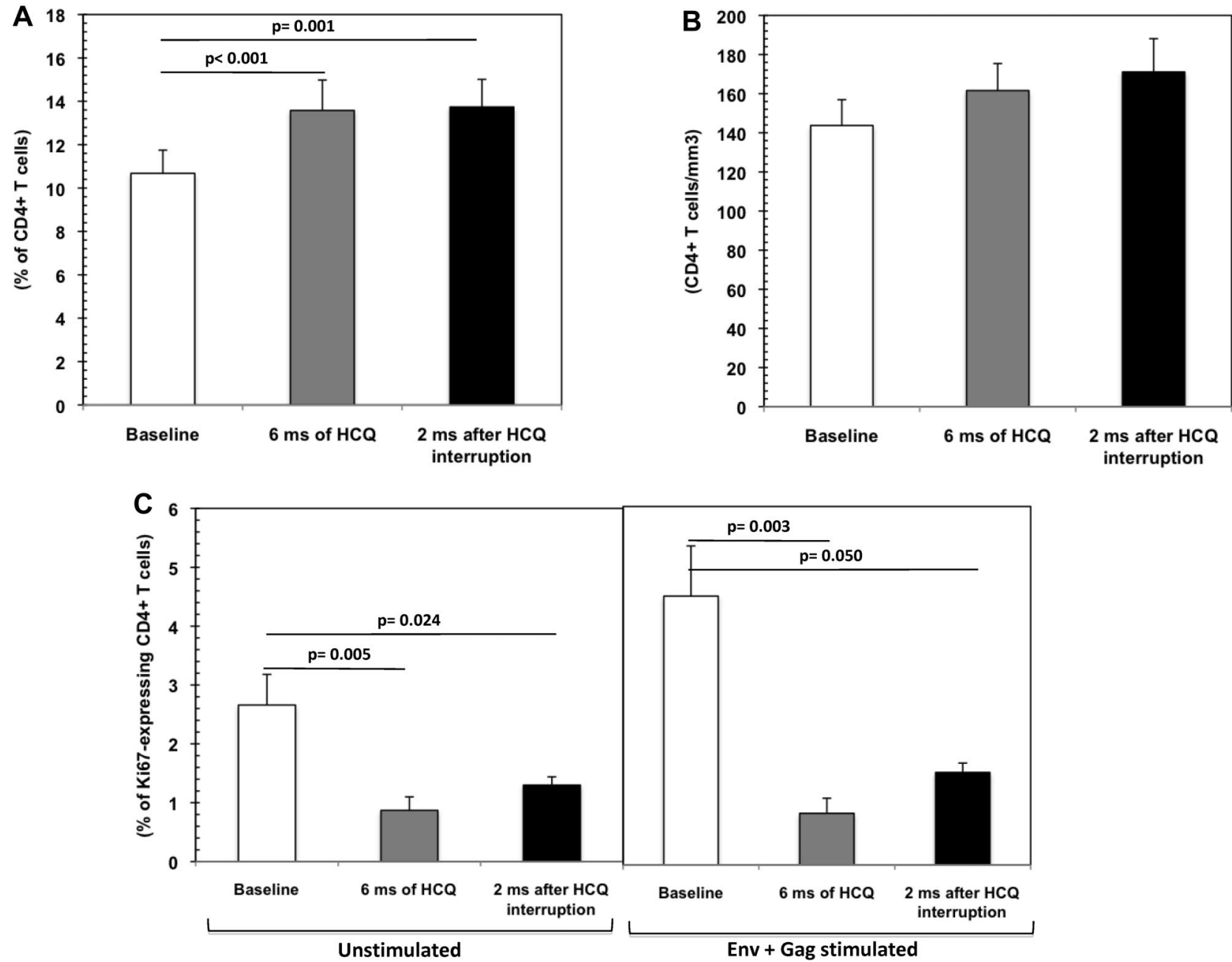

Figure 1. CD4 ${ }^{+} \mathrm{T}$ cells in HCQ-treated patients. Percentage of CD4 ${ }^{+} \mathrm{T}$ cells $(\mathrm{A})$ and $\mathrm{CD} 4^{+} \mathrm{T}$-cell counts (B) in HIV-infected INRs at baseline ( $\square$ ), after 6 months (ms) of HCQ (圆), and 2 months after HCQ interruption ( $\square)$. Panel $C$ shows unstimulated and env + gag-stimulated activated Ki67 ${ }^{+} \mathrm{CD} 4^{+} \mathrm{T}$ cells in $\mathrm{HIV}$-infected INRs analyzed at the same time points. Mean values, SE, and $P$ values are indicated.

and $P=.041$, respectively, Figure 2A), whereas (2) $\mathrm{CD}^{+} 9^{+} \mathrm{CD} 8^{+}$ and $\mathrm{CD} 38^{+} \mathrm{CD} 45 \mathrm{RO}^{+} \mathrm{CD}^{+}$cells were significantly augmented compared with month $6(P=.043$ and $P=.039$, respectively, Figure 2B-C).

Finally, CD69-expressing CD14 ${ }^{+}$cells were also significantly reduced after 6 months of HCQ treatment $(P=.04)$. Percentages of these cells returned to the baseline values after 2 months of HCQ interruption (Figure 2D).

\section{TLR expression on monocytes}

HCQ downmodulates the expression of intracellular TLR in vitro and in the murine model. The effect of this compound in HIV infection was analyzed by evaluating TLR2, TLR4, TLR5, TLR7, and TLR8 expression on CD14 ${ }^{+}$cells both in whole blood and on stimulation with specific antagonist. Results obtained in whole blood showed that HCQ induced a significant reduction in TLR2-, TLR4-, and TLR5-expressing CD14 ${ }^{+}$cells (TLR2, $P=.032$; TLR4, $P=.004$; TLR5, $P=.008$; Figure 3A-C). Results obtained when cell cultures were stimulated with TLR agonists showed a significant reduction in LPS-stimulated cells alone (TLR4, $P=.006$; Figure 3D) that vanished 2 months after interruption of HCQ $(P=.050)$. In contrast, no changes in ssRNA-stimulated TLR7and TLR8-expressing CD14 ${ }^{+}$cells were detected (Figure 3E-F).

\section{Tregs and TLR-expressing Tregs}

Tregs were evaluated both in whole blood and with HIV-specific stimulation. Both naive (PD1 ${ }^{\text {neg }}$ ) and activated (PD1 $\left.{ }^{\text {pos }}\right)$ Tregs were significantly increased after HCQ; this effect persisted 2 months after HCQ interruption (Figure 4A-B).

TLR2 and TLR4 expression on Tregs was evaluated in whole blood and with HIV-specific stimulation; TLR4-expressing Tregs were also analyzed on LPS stimulation. As shown in Figure 4C through E, TLR2- and TLR4-expressing Tregs were significantly augmented after HCQ, and this increase was maintained 2 months after HCQ suspension in all culture conditions (Figure 4C-E). Thus, the observed increase in Tregs induced by HCQ was at least partially supported by TLR2- and TLR4-expressing cells.

\section{pDCs}

pDCs represent a unique and crucial immune cell population capable of producing large amounts of type I IFNs in response to viral infection. The percentage of pDCs was significantly augmented after 6 months of HCQ treatment; this effect persisted 2 months after HCQ interruption $(P<.001$ in both cases; Figure $5 \mathrm{~A})$. Of note, IFN $\alpha$-secreting pDCs were diminished during HCQ treatment and 2 months after HCQ suspension $(P<.05$ in both cases; Figure 5B). 

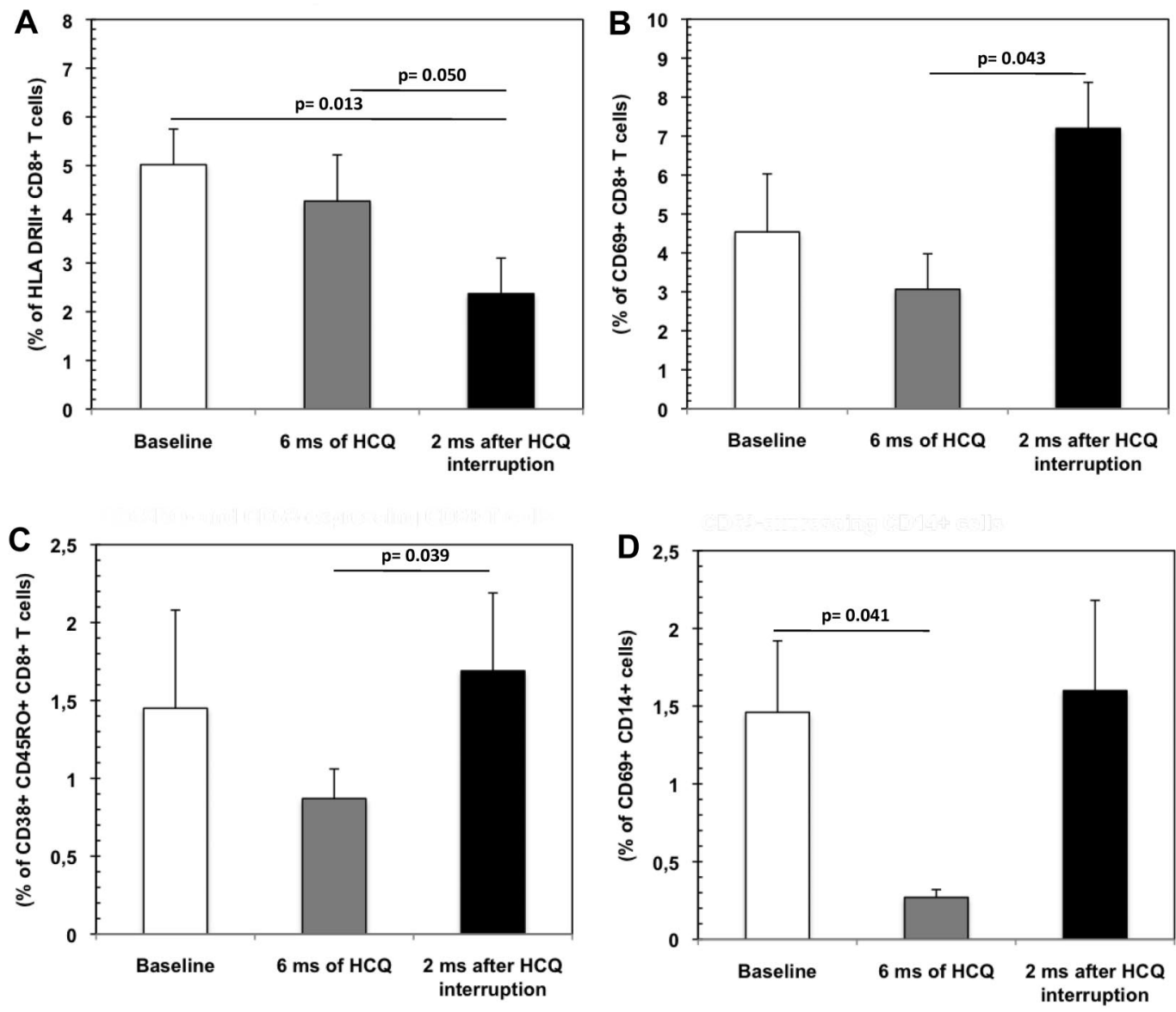

Figure 2. Effect of $\mathrm{HCQ}$ on activated $\mathrm{CD} 8^{+} \mathrm{T}$ cells and $\mathrm{CD} 14^{+}$monocytes. $\mathrm{CD} 8^{+} \mathrm{DRII}{ }^{+}(\mathrm{A}), \mathrm{CD}^{+} \mathrm{CD}^{+} 9^{+}(\mathrm{B})$, and $\mathrm{CD} 8^{+} \mathrm{CD} 38^{+} \mathrm{CD} 45 \mathrm{RO}{ }^{+}(\mathrm{C}) \mathrm{T}$ cells $($ percentage) and $\mathrm{CD}_{14}{ }^{+} \mathrm{CD}_{69}{ }^{+}$activated monocytes (percentage; D) in HIV-infected INRs at baseline, after 6 months of $\mathrm{HCQ}$, and 2 months after HCQ interruption. Mean values, SE, and $P$ values are indicated.

\section{Proinflammatory cytokines}

IL- 6 and $\mathrm{TNF} \alpha$ production by $\mathrm{CD} 14^{+}$and $\mathrm{CD} 4^{+} \mathrm{T}$ cells was analyzed in unstimulated and in LPS-, ssRNA-, and env + gagstimulated conditions; the plasma concentration of these cytokines was evaluated as well. Results showed IL-6- and TNF $\alpha$-secreting $\mathrm{CD}_{14}{ }^{+}$and $\mathrm{CD}^{+}$cells to be diminished after HCQ treatment, reaching statistical significance only for ssRNA-stimulated CD14 ${ }^{+}$ cells (Table 2). The plasma IL-6 concentration was significantly reduced after HCQ treatment as well (Table 2).

\section{Plasma LPS levels}

The plasma LPS concentration is an index of microbial translocation; an augmented LPS concentration is associated with alterations of the gut permeability. HCQ treatment induced a reduction in LPS plasma concentration that was maintained after interruption of therapy (baseline vs 2 months after interruption, $P=.03 ; 6$ months HCQ vs 2 months after interruption, $P=.001$; Figure 6).

\section{TLR signaling pathway}

Besides having an effect on TLR expression, HCQ reduces TLR-mediated signal transduction in vitro and in the murine model. To evaluate whether a similar effect could be seen in vivo in HIV-infected patients, TLR-mediated signaling pathways were evaluated using an RT-PCR array screening for the expression of 84 genes involved in such pathways. Engagement of TLR7/8 with specific agonists at baseline resulted in the activation of TLR-signaling pathways as demonstrated by increased expression of mediators involved in the transduction pathway (MAP2K3, MAP2K4 MAP3K1, MAP3K7, MAP3K7IP1, MAP4K4, MAPK8, MAPK8IP3, MYD88, NFKB1, NFKB2, NFKBIA, NFKBIL1, NFRKB, NR2C2, PELI1, PPARA, PRKRA, REL, RELA, RIPK2, SARM1, SIGIRR, ECSIT, TBK1, TICAM2, and TIRAP) and of effector molecules (CSF2, CSF3, IL-12, IL-1, IL-6, IL-10, IL-12, and PTGS2). After 6 months of HCQ therapy, however, TLR7/8 responsiveness was markedly downmodulated, and it was not restored even after therapy suspension. Of note, TLR7 and TLR 8 mRNA specific expression progressively decreased from baseline to suspension of HCQ treatment, suggesting a possible explanation for the decreased responsiveness observed after ssRNA stimulation (Figure 7).

Data collected after TLR4 stimulation resembled the immunologic profile observed in TLR7/8-stimulated PBMCs. Thus, at baseline PBMCs were highly responsive to LPS, and HCQ therapy resulted in a marked inhibition of the TLR4 pathway that persisted after treatment suspension. Similarly to what was observed for TLR7/8, the gradual decrease in cytokine/chemokine expression after LPS stimulation was accompanied by reduced expression of TLR4 mRNA (Figure 7). 

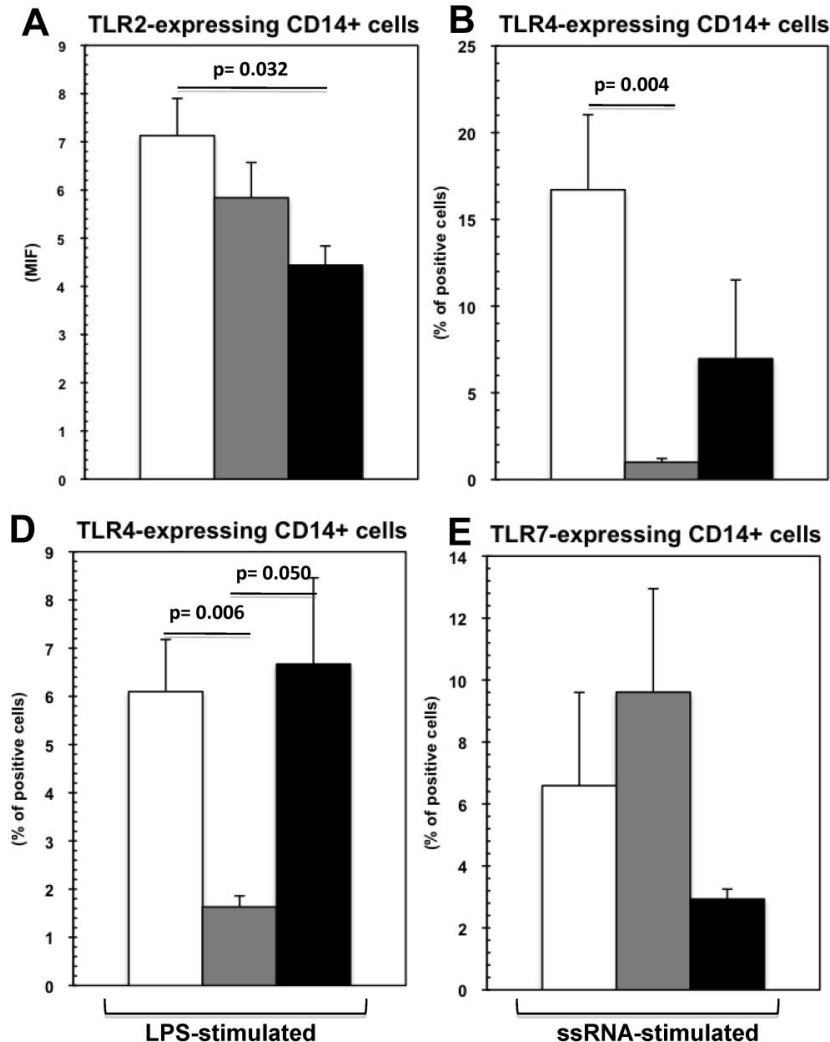
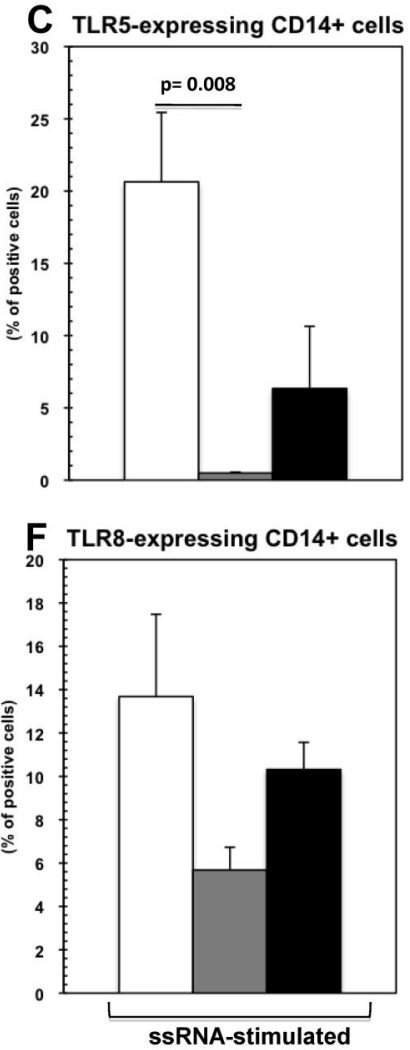

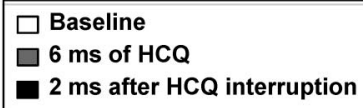

Figure 3. TLR-expressing CD14 ${ }^{+}$monocytes are reduced in HCQ-treated patients. $\mathrm{TLR2}^{+}(\mathrm{A})$, $\mathrm{TLR}^{+}(\mathrm{B})$, and $\mathrm{TLR}^{+}(\mathrm{C}) \mathrm{CD} 14^{+}$monocytes $($percentage) in whole blood in HIV-infected INRs at baseline, after 6 months $(\mathrm{ms})$ of HCQ treatment, and 2 months after HCQ interruption. LPS-stimulated TLR4 $^{+}$(D), ssRNA-stimulated TLR7 ${ }^{+}$(E), and $\mathrm{TLR}^{+}$(F) $\mathrm{CD}_{14}^{+}$monocytes (percentage) in the same individuals. Mean values, SE, and $P$ values are indicated.

\section{Discussion}

The underlying causes of the immune activation seen in HIV infection are still not fully clarified, but one of the most validated and solid hypotheses to explain this phenomenon stems from the observation that acute HIV infection is associated with a rapid and probably irreversible destruction of the $\mathrm{CD} 4{ }^{+} \mathrm{T}$ cell population that resides in gut-associated lymphoid tissues. ${ }^{20-23}$ Loss of mucosal integrity results in impaired local cellular immunity and translocation of microbial products, including LPS, which contribute to persistent inflammation through TLR activation. ${ }^{19-23}$ Because LPS ligates TLR4, a molecule expressed on a variety of immune cells, the LPS/TRL4 axis has been postulated as being responsible for HIV-associated immune activation. Of note, the non-AIDS comorbidities that are more common in ART-treated patients with persistently reduced $\mathrm{CD} 4^{+} \mathrm{T}$ cells despite fully satisfactory suppression of viral replication (immunologic nonresponders) were recently suggested to be mainly associated with immune activation.

HCQ downregulates TLR signaling and reduces the production of inflammatory cytokines. On the basis of this assumption we verified whether this compound could modulate immune activation and $\mathrm{CD}^{+}{ }^{+} \mathrm{T}$-cell counts in INRs. Results herein indicate that HCQ has a significant effect on immune activation, as shown by the reduction of circulating activated immune cells, the downmodulation of TLR expression and of TLR-mediated signal transduction, and the decreased production of IL-6. This effect is probably associated with the increased concentration of Treg lymphocytes and the reduced quantities of serum LPS observed in HCQ-treated individuals and is accompanied by significantly augmented percentages of circulating $\mathrm{pDC}$.
Of note, HCQ-associated reduction of immune activation was mostly retained after therapy interruption and was accompanied by a real increase in $\mathrm{CD}^{+}{ }^{+} \mathrm{T}$-cell percentage, because total lymphocyte counts did not change during the study period. This reduction of immune activation was also associated with a similar trend, albeit not reaching statistical significance, in $\mathrm{CD} 4^{+} \mathrm{T}$-cell counts. These data suggest that HCQ is effective in reducing CD4 ${ }^{+} \mathrm{T}$-cell activation, resulting in an increase in $\mathrm{CD}^{+}{ }^{+} \mathrm{T}$-cell percentage. We have shown the presence of upregulation of the LPS/TLRdependent immune activation in HIV-infected individuals lacking CD4 normalization during $\mathrm{ART},{ }^{23}$ and recently a reduction in immune activation and a decrease in $\mathrm{CD} 38^{+} \mathrm{CD} 8^{+} \mathrm{T}$ cells and of $\mathrm{Ki}-67$ memory $\mathrm{CD}^{+}{ }^{+} \mathrm{T}$ cells was reported in ART-treated and naive HIV-infected patients treated with HCQ. ${ }^{19}$ Data herein confirm and expand those results and indicate a possible therapeutic benefit of HCQ in ART-treated individuals in whom a satisfactory recovery of $\mathrm{CD}^{+}{ }^{+} \mathrm{T}$ cells is not achieved.

HCQ was effective in reducing the percentage of proliferating $\mathrm{CD}^{+} \mathrm{T}$ lymphocytes and of activated $\left(\mathrm{CD} 69^{+}\right)$monocytes, whereas its effect on $\mathrm{CD}^{+} \mathrm{T}$ cells was marginal, indicating a possible lack of effect of HCQ on this lymphocyte population. Of note, the use of this compound resulted in increased percentages of circulating Tregs. The role of these cells in HIV infection is still not totally clarified, but it is likely that the destruction or inactivation of Tregs by HIV would result in a lack of control over immune activation. ${ }^{37,38}$ Treg-mediated suppression of antigen-specific responses in vitro was shown to be more effective with cells isolated from relatively healthy HIV-infected individuals compared with those from patients with later-stage AIDS, suggesting that Tregs (total or HIV-specific) are depleted and/or dysfunctional later in HIV disease. ${ }^{39}$ HCQ treatment induced an increase in naive and 

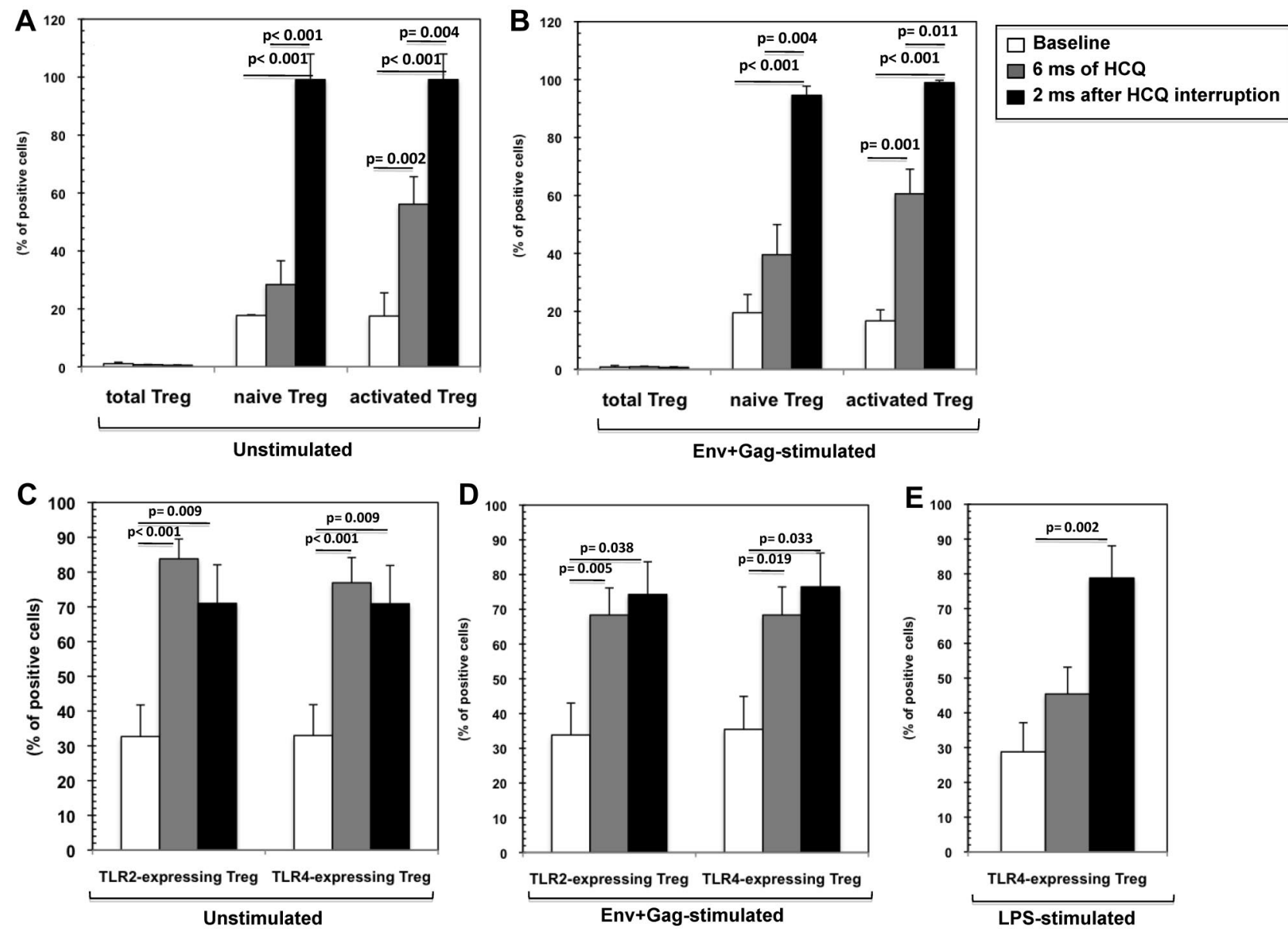

Figure 4. Tregs and TLR-expressing Tregs are increased in HCQ-treated patients. Unstimulated (A) and env + gag-stimulated (B) total, naive, and activated Treg (\%) in HIV-infected INRs at baseline, after 6 months (ms) of HCQ treatment, and 2 months after HCQ interruption. Unstimulated (C) and env + gag-stimulated (D) TLR2 ${ }^{+}$and TLR4 ${ }^{+}$ Tregs and LPS-stimulated (E) TLR4 ${ }^{+}$Tregs (percentage) in the same patients. Mean values, SE, and $P$ values are indicated.

activated Tregs in both unstimulated and HIV-infected specific populations. These subpopulations of Tregs are endowed with strong immunosuppressive activity and probably play a role in the ability of HCQ to reduce immune activation. Of note, the increases in Tregs seen as a result of HCQ were at least partially supported by TLR2- and TLR4-expressing cells; these subpopulations of Tregs were shown to mediate a strong immunosuppressive activity. ${ }^{40}$

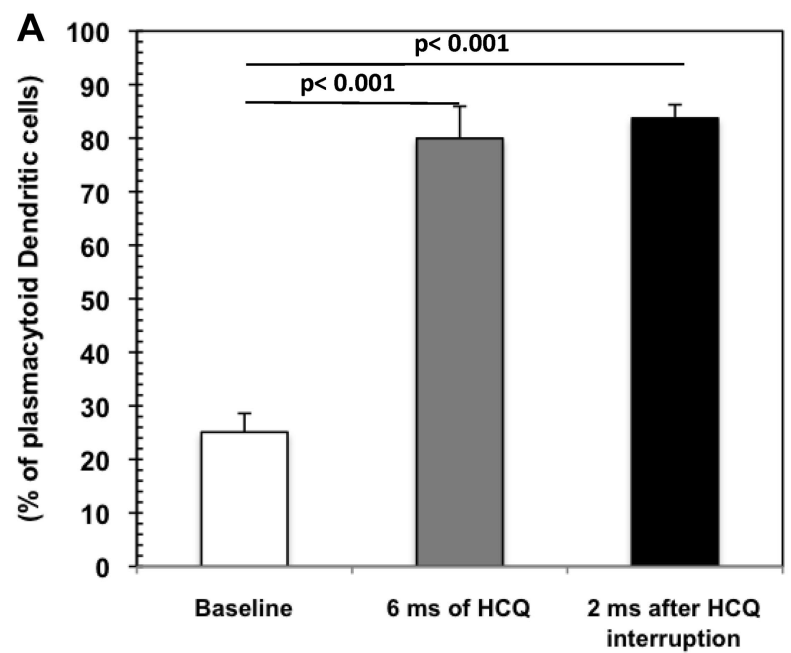

HCQ was also associated with an effect on pDC because these cells were augmented in HCQ-receiving individuals. pDCs are low-frequency cells found in peripheral blood and lymphoid tissues that are best known for their ability to produce large quantities of IFN $\alpha$ in response to viruses. An impairment in $\mathrm{pDC}$ function was described in HIV infection and in the pre-ART era pDCs were shown to inversely correlate with $\mathrm{CD}^{+} \mathrm{T}$ counts and viral loads.

Figure 5. pDCs are increased in HCQ-treated patients. pDCs (A) and IFN $\alpha$-secreting pDCs (percentage; B) in HIV-infected INR patients at baseline ( $\square$ ), after 6 months (ms) of $\mathrm{HCQ}$ treatment (圆), and 2 months after $\mathrm{HCQ}$ interruption (口). Mean values, SE, and $P$ values are indicated.

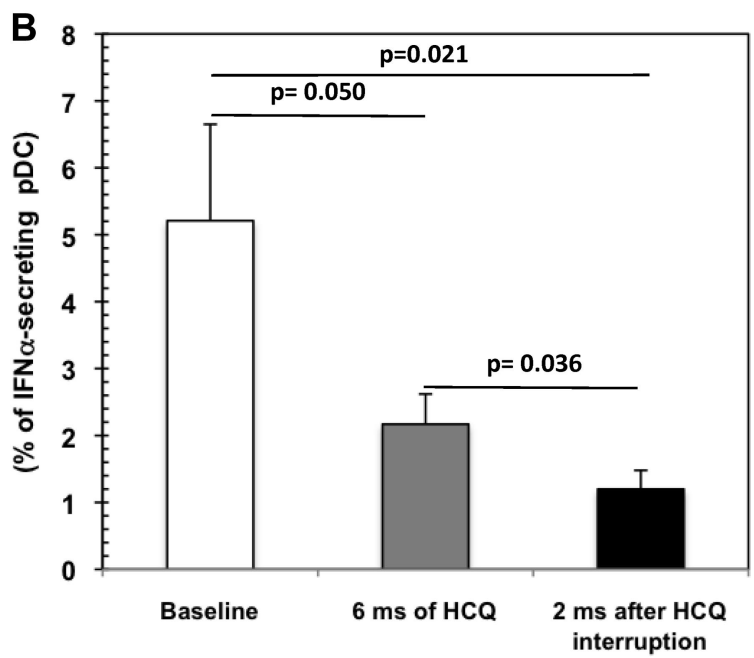


Table 2. IL6 and TNF $\alpha$ production in HCQ-treated patients

\begin{tabular}{|c|c|c|c|c|}
\hline & Baseline & $6 \mathrm{mo}$ of $\mathrm{HCQ}$ & 2 mo after $\mathrm{HCQ}$ interruption & $\boldsymbol{P}$ \\
\hline \multicolumn{5}{|c|}{ LPS-stimulated PBMCs, \% positive } \\
\hline $\mathrm{IL}-6^{+} \mathrm{CD} 14^{+}$cells & $63.94 \pm 5.91$ & $42.63 \pm 4.95$ & $62.00 \pm 5.10$ & NS \\
\hline $\mathrm{TNF}^{+}{ }^{+} \mathrm{CD} 14^{+}$cells & $53.71 \pm 3.87$ & $40.56 \pm 5.43$ & $51.90 \pm 4.10$ & NS \\
\hline \multicolumn{5}{|c|}{ ssRNA-stimulated PBMCs, \% positive } \\
\hline IL-6 ${ }^{+}$CD $14^{+}$cells & $67.76 \pm 3.70$ & $58.99 \pm 4.39$ & $37.00 \pm 5.00$ & 6 mo vs 2 mo: 0.007 \\
\hline $\mathrm{TNF}{ }^{+} \mathrm{CD} 14^{+}$cells & $78.30 \pm 3.20$ & $64.42 \pm 3.32$ & $69.39 \pm 5.10$ & Baseline vs 6 mo: 0.038 \\
\hline \multicolumn{5}{|c|}{ Env + gag-stimulated PBMCs, \% positive } \\
\hline IL- $6^{+} \mathrm{CD} 4^{+}$cells & $1.71 \pm 0.94$ & $1.62 \pm 0.58$ & $3.37 \pm 1.70$ & NS \\
\hline $\mathrm{TNF}^{+} \mathrm{CD}^{+}$cells & $3.37 \pm 1.70$ & $2.66 \pm 0.39$ & $5.07 \pm 1.24$ & NS \\
\hline \multicolumn{5}{|c|}{ Plasma cytokine concentrations, pg/mL } \\
\hline IL-6 & $5.78 \pm 2.66$ & $2.42 \pm 0.80$ & $1.18 \pm 0.21$ & Baseline vs 2 mo: 0.048 \\
\hline $\mathrm{TNF} \alpha$ & $8.55 \pm 1.46$ & $8.85 \pm 2.42$ & $27.41 \pm 7.78$ & NS \\
\hline
\end{tabular}

Data are presented as mean \pm SE.

NS indicates not significant.

These observations, together with the facts that ART increases pDC counts and that higher levels of $\mathrm{pDC}$ are seen in long-term nonprogressors, led to the suggestion that $\mathrm{pDCs}$ play a protective role against the progression of HIV infection. ${ }^{41-46}$ Although IFN $\alpha$ reduces viral burden in the acute phases of infection, elevated levels of this cytokine in advanced HIV diseases are associated with increased microbial translocation and could contribute to immune activation. Of note, despite increasing the number of pDCs, HCQ reduced IFN $\alpha$ production by these cells. IFN $\alpha$ production by pDCs is dependent on TLR9 engagement. ${ }^{18} \mathrm{We}$ did not directly examine the TLR9 pathway but rather concentrated on TLR7/8 and TLR4. Nevertheless, because we saw decreased mRNA synthesis for these 3 TLRs, as well as downregulation of TLR 7/8 and 4 signaling pathways, it is possible to speculate that reduced expression of TLR9 on pDCs and/or diminished efficacy of the TLR9-mediated signaling could justify the reduced IFN $\alpha$ production seen in pDCs of HCQ-treated individuals. In-depth analyses will be needed to clarify the exact mechanisms. Finally, whereas pDCs activated through TLR7 and TLR9 work as antiviral cells via IFN $\alpha$, it was recently suggested that non-IFN $\alpha$-producing pDCs can act as tolerogenic cells promoting Treg activation via the indoleamine 2,3-dioxygenase and programmed death 1 pathways. ${ }^{47}$ Data herein suggest that this phenomenon could take place in vivo in HCQ-treated individuals.
The use of HCQ resulted also in the downmodulation of IL6 production by immune cells, an effect that was previously shown to be associated with this drug. More interesting was the reduction of LPS plasma levels seen in HCQ-treated patients; this observation suggests an improvement in gut mucosa permeability. It will be interesting to determine whether this is a direct consequence of HCQ or rather a consequence of the reduced peripheral immune activation seen in these patients. These considerations notwithstanding, because LPS directly triggers TLR4-expressing immune cells, the HCQ-associated reduction of plasmatic LPS probably plays a major role in the effect on immune activation by HCQ described herein.

An important caveat of results herein is that the robust reduction of immune activation achieved by HCQ was not reflected in a similarly important increase in the absolute number of $\mathrm{CD}^{+}$ T cells: a trend, not a significant amelioration, was observed. This discrepancy raises several interesting questions: (1) Is the effect of HCQ not potent enough to convincingly modify $\mathrm{CD}^{+} \mathrm{T}$ cells in patients who are not able to respond immunologically to potent ART? (2) Is immune activation the only cause responsible for lack of $\mathrm{CD} 4^{+} \mathrm{T}$-cell recovery in these patients? And, finally, (3) Will the immune changes induced by HCQ be sufficient to positively affect the clinical outcome of these individuals? All the patients are
Plasma LPS concentration

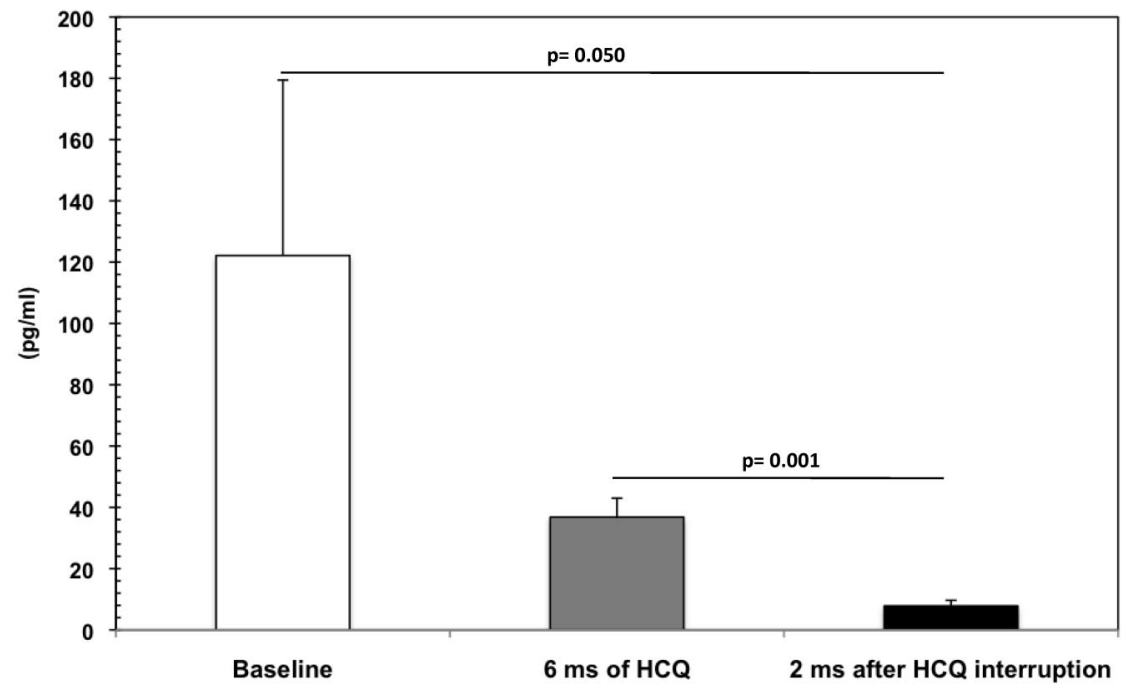

Figure 6. Plasma LPS levels are reduced in HCQtreated patients. Plasma LPS concentrations in HIVinfected INRs at baseline ( $\square$ ), after 6 months (ms) of $\mathrm{HCQ}$ treatment (圆), and 2 months after HCQ interruption (घ). Mean values, SE, and $P$ values are indicated. 
A TLR signalling pathway following TLR4 stimulation

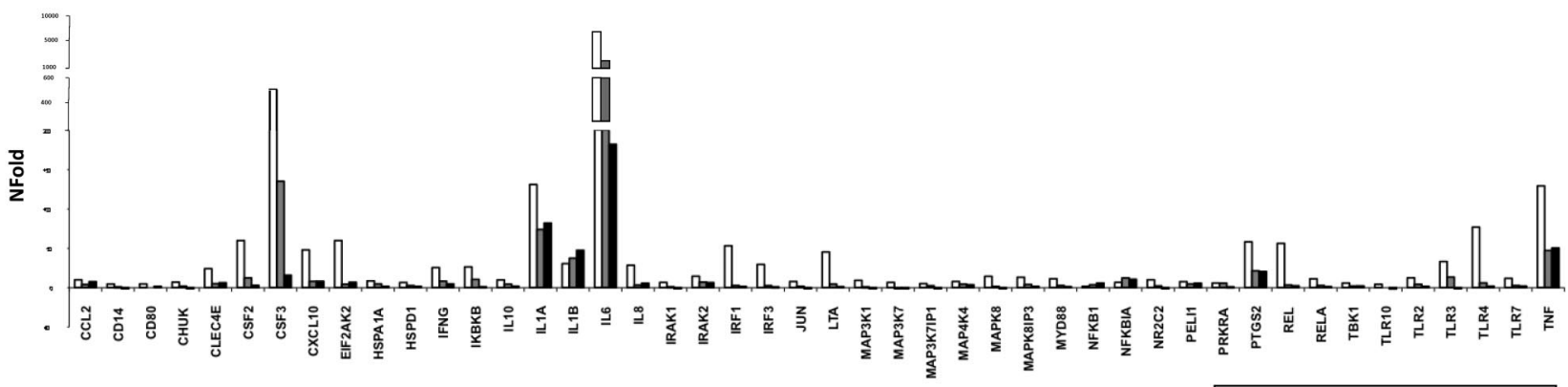

B TLR signalling pathway following TLR7/8 stimulation $\square$ Baseline

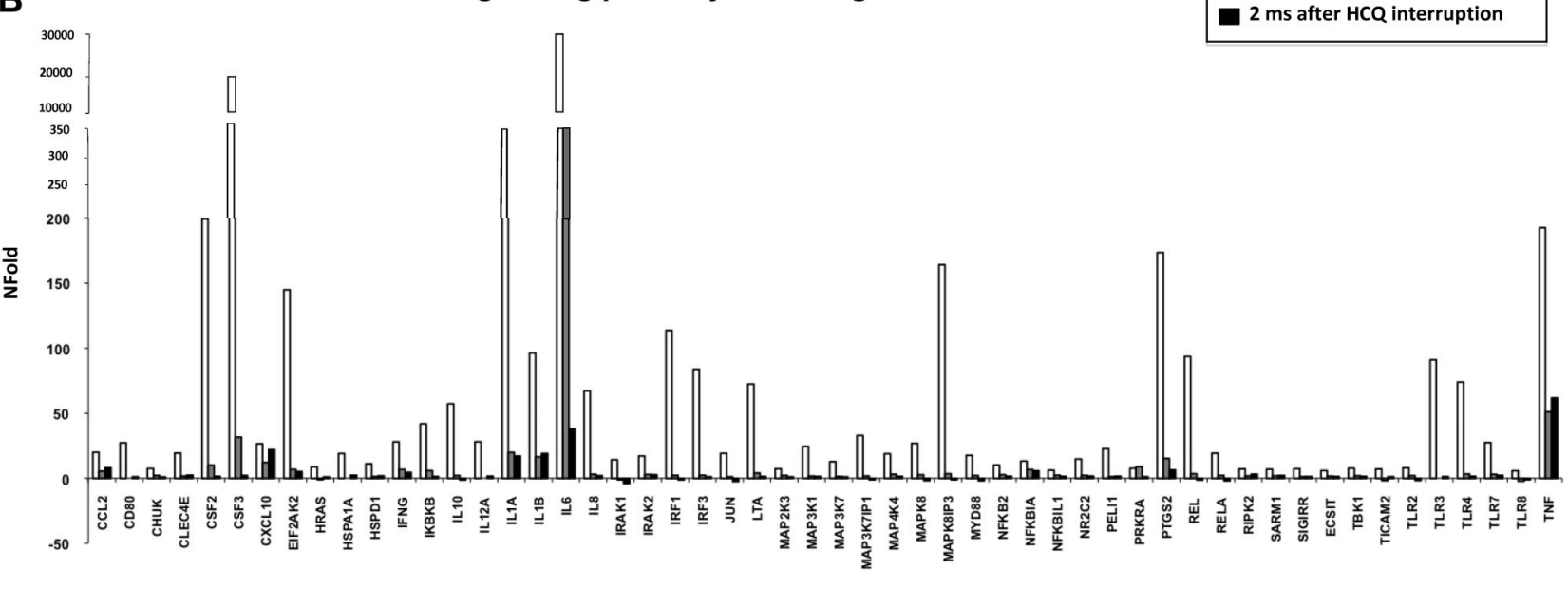

Figure 7. TLR4 and TLR7/8 signaling pathways are downmodulated in HCQ-treated patients. TLR signaling pathway after TLR4 (A) and TLR7/8 stimulation (B) in HIV-infected INRs. Results obtained at baseline, after 6 months $(\mathrm{ms})$ of $\mathrm{HCQ}$ treatment, and 2 months after HCQ interruption are shown. Mean values, SE, and $P$ values are indicated.

followed at regular time intervals; results from the follow-up will at least in part clarify these issues.

In conclusion, our data suggest that HCQ has beneficial effects on TLR/LPS-mediated immune activation, the possible cause of lack of $\mathrm{CD}^{+}{ }^{+} \mathrm{T}$-cell recovery and of associated comorbidity in INRs. HCQ could be considered to be a useful immunomodulating drug in particular groups of $\mathrm{HIV}$-infected patients.

\section{Acknowledgments}

This study was supported by grants from the Istituto Superiore di Sanità "Programma Nazionale di Ricerca sull'AIDS," the EMPRO and AVIP EC WP6 Projects, the nGIN EC WP7 Project, the Japan Health Science Foundation, 2007 Ricerca Finalizzata (Italian Ministry of Health), 2007 Ricerca Corrente (Italian Ministry of
Health), and progetto FIRB RETI, Rete Italiana Chimica Farmaceutica CHEM-PROFARMA-NET (RBPR05NWWC).

\section{Authorship}

Contribution: S. Piconi, D.T., and M.C. designed the study and wrote the manuscript; S. Parisotto conducted cellular analyses; G.R., S. Passerini, R.T., B.A., P.M., and A.C. selected patients and performed clinical analyses; and M.B. conducted PCR analyses.

Conflict-of-interest disclosure: The authors declare no competing financial interests.

Correspondence: Prof Mario Clerici, MD, Chair of Immunology, University of Milano, Department of Biomedical Sciences and Technologies, Via F.lli Cervi 93, 20090 Segrate (Milano), Italy; e-mail: mario.clerici@unimi.it

\section{References}

1. Sperber K, Quraishi H, Kalb TH, Panja A, Stecher V, Mayer L. Selective regulation of cytokine by hydroxychloroquine: inhibition of interleukin-1 alpha (IL-1 alpha) and IL-6 in human monocytes and T cells. J Rheumatol. 1993;20(5):803808.

2. Karres I, Kremer JP, Dietl I, Steckholzer U, Jochum M, Ertel W. Chloroquine inhibits proinflammatory cytokines release into human whole blood. Am J Physiol. 1998;274:R1058-R1064.

3. Popert AJ, Mejers KA, Sharp J, Bier F. Chloro- quine diphosphate in rheumatoid arthritis: a controlled trial. Ann Rheum Dis. 1961;20:18-24.

4. Tsokos GC. Immunomodulatory treatment in patients with rheumatic disease: mechanisms of action. Semin Arthritis Rheum. 1987;17(1):24-38.

5. Fox RI, Chan E, Benton L, Fong S, Friedlaender M, Howell FV. Treatment of primary Sjögren's syndrome with hydroxychloroquine. Am J Med. 1988;85(4A):62-67.

6. Fox RI. Mechanism of action of hydroxychloro- quine as an antirheumatic drug. Semin Arthritis Rheum. 1993;23(2 suppl 1):82-91.

7. Ohkuma S, Poole B. Cytoplasmic vacuolation of mouse peritoneal macrophages and the uptake into lysosomes of weakly basic substances. J Cell Biol. 1981;90(3):656-664.

8. Hong Z, Jiang Z, Liangxi W, et al. Choroquine protects mice from challenge with $\mathrm{CpG}$ ODN and LPS by decreasing proinflammatory cytokine release. Int Immunopharmacol. 2004;4(2):223-234. 
9. Sperber K, Kalb TH, Stecher VJ, Banerjee R, Mayer L. Inhibition of human immunodeficiency virus type 1 replication by hydroxychloroquine in T cells and monocytes. AIDS Res Hum Retroviruses. 1993;9(1):91-98.

10. Pazmiño NH, Yuhas JM, Tennani RW. Inhibition of murine RNA tumor virus replication and oncogenesis by chloroquine. Int J Cancer. 1974;14(3): 379-389.

11. Savarino A, Gennero L, Chen HC, et al. Anti-HIV effects of chloroquine: mechanism of inhibition and spectrum of activity. AIDS. 2001;15(17): 2221-2229.

12. Sperber K, Kalb TH, Stecher VJ, Banerjee R, Mayer L. Inhibition of human immunodeficiency virus type 1 replication by hydroxychloroquine in T cells and monocytes AIDS Res Hum Retrovirus. 1993;9(1):91-98.

13. Jiang MC, Lin JK, Chen SS. Inhibition of HIV-1 Tat-mediated transactivation by quinacrine and chloroquine. Biochem Biophys Res Commun. 1996;226(1):1-7.

14. Naarding MA, Baan E, Pollakis G, Paxon WA Effects of chloroquine on reducing HIV-1 replication in vitro and the DC-SIGN mediated transfer of virus to CD4+ T-lymphocytes. Retrovirology. 2007;4:6-18.

15. Sperber K, Louie M, Kraus T, et al. Hydroxychloroquine treatment of patients with human immunodeficiency virus type 1. Clin Ther. 1995;17(4): 622-636.

16. Sperber K, Chiang G, Chen H, et al. Comparison of hydroxychloroquine with zidovudine in asymptomatic patients infected with human immunodeficiency virus type 1. Clin Ther. 1997;19:913-923.

17. Paton NI, Aboulhab J, Karim F. Hydroxychloroquine, hydroxycarbamide and didanosine as economic treatment for HIV-1. Lancet. 2002; 359(9318):1667-1668

18. Martinson JA, Montoya CJ, Usuga X, Ronquillo R, Landay AL, Desai SN. Chloroquine modulates HIV-1-induced plasmacytoid dendritic cell alpha interferon: implication for T cell activation. Antimicrob Agents Chemother. 2010;54(2): 871-881.

19. Murray SM, Down CM, Boulware DR, et al. Reduction of immune activation during chronic HIV infection with chloroquine therapy. $J$ Virol. 2010; 84(22):12082-12086.

20. French MA, King MS, Tschampa JM, da Silva BA, Landay AL. Serum immune activation markers are persistently increased in patients with HIV infection after 6 years of antiretroviral therapy despite suppression of viral replication and reconstitution of CD4+ T cells. J Infect Dis. 2009;200(8): 1212-1215.

21. Brenchley JM, Price DA, Schacker TW, et al. Microbial translocation is a cause of systemic immune activation in chronic HIV infection. Nat Med. 2006;12(12):1365-1371.

22. Funderburg $N$, Luciano AA, Jiang $W$, Rodriguez B, Sieg SF, Lederman MM. Toll-like receptor ligands induce human $\mathrm{T}$-cell activation and death, a model for HIV pathogenesis. PLOS One. 2008;3(4):e1915.
23. Benveniste O, Flahault A, Rollot F, et al. Mechanisms involved in the low-level regeneration of CD4+ cells in HIV-1-infected patients receiving highly active antiretroviral therapy who have prolonged undetectable plasma viral loads. J Infect Dis. 2005;191(10):1670-1679.

24. Pitrak DL, Bolanos J, Hershow R, Novak RM Discordant CD4 T lymphocyte responses to antiretroviral therapy for HIV infection are associated with ex-vivo rates of apoptosis. AIDS. 2001; 15(10):1317-1319.

25. Marchetti G, Bellistri GM, Borghi E, at al. Microbial translocation is associated with sustained failure in CD4+ T-cell reconstitution in HIV-infected patients on long-term highly active antiretroviral therapy. AIDS. 2008;22(15):2035-2038.

26. Marchetti G, Gori A, Casabianca A, et al. Comparative analysis of $T$ cell turnover and homeostatic parameters in HIV-infected patients with discordant immune-virologic responses to HAART. AIDS. 2006;20(13):1727-1736.

27. Ostrowski SR, Katzenstein TL, Thim PT, Petdersen BK, Gerstoft J, Ullum H. Low-level viremia and proviral DNA impede immune reconstitution in HIV-1 infected patients receiving highly active antiretroviral therapy. J Infect Dis. 2005; 191(3):348-357.

28. Chun TW, Shawn Justement TL, Pandya $P$, et al. Relationship between the size of the human immunodeficiency virus type 1 (HIV-1) reservoir in peripheral blood CD4+ T cells and CD4+:CD8+ T cell ratios in aviremic HIV-1-infected individuals receiving long-term highly active antiretroviral therapy. J Infect Dis. 2002;185(11):1672-1676.

29. García F, Vidal C, Plana M, et al. Residual lowlevel viral replication could explain discrepancies between viral load and CD4+ cell response in human immunodeficiency virus-infected patients receiving antiretroviral therapy. Clin Infect Dis. 2000;30(2):392-394

30. Giorgi JV, Majchrowicz MA, Johnson TD, Hultin P Matud J, Detels R. Immunological effects of combined protease inhibitor and reverse transcriptase inhibitor therapy in previously treated chronic HIV-1 infection. AIDS. 1998;12(14):1833-1844.

31. Havlir DV, Strain MC, Clerici M, et al. Productive infection maintains a dynamic steady state of residual viremia in human immunodeficiency virus type-1 infected persons treated with suppressive antiretroviral therapy for five years. J Virol. 2003; 77(20):11212-11219.

32. Sabbatini F, Bandera A, Ferrario G et al Qualitative immune modulation by interleukin-2 (IL-2) adjuvant therapy in immunological non responder HIV-infected patients. PLoS One. 2010;5(11): e14119.

33. Piconi S, Trabattoni D, Gori A, et al. Immune activation, apoptosis, and Treg activity are associated with persistently reduced CD4 + T-cell counts during antiretroviral therapy. AIDS. 2010; 24(13):1991-2000

34. Clerici M, Stocks NI, Zajac RA, et al. Interleukin-2 production used to detect antigenic peptide recognition of HIV synthetic peptides recognition by Thelper lymphocytes from asymptomatic HIV- seropositive individuals. Nature. 1989;339:383386.

35. Saresella M, Marventano I, Longhi R, et al. CD4+CD25+FoxP3+PD1- regulatory T cells in acute and stable relapsing-remitting multiple sclerosis and their modulation by therapy. FASEB J. 2008;22(10):3500-3508.

36. Biasin M, Piacentini L, Lo Caputo S, et al. TLR activation pathways in HIV-1-exposed seronegative individuals. J Immunol. 2010;184(5):27102717

37. Oswald-Richter K, Grill SM, Shariat N, et al. HIV infection of naturally occurring and genetically reprogrammed human regulatory T-cells. PLOS Biol. 2004;2:E198.

38. Apoil PA, Puissant B, Roubinet F, et al. FOXP3 mRNA levels are decreased in peripheral blood CD4+ lymphocytes from HIV-positive patients. J Acquir Immune Defic Syndr. 2005;39:381-385.

39. Kinter AL, Hennessey M, Bell A, et al. CD25+CD4+ regulatory T cells from the peripheral blood of asymptomatic HIV-infected individu als regulate CD4+ and CD8+ HIV-specific T cell immune responses in vitro and are associated with favorable clinical markers of disease status. J Exp Med. 2004;200(3):331-343.

40. Caramalho I, Lopes-Carvalho T, Ostler D, Zelenay S, Haury M, Demengeot J. Regulatory T cells selectively express Toll-like receptors and are activated by lipopolysaccharide. J Exp Med. 2003;197(4):403-411.

41. Soumelis V, Scott I, Gheyas F, et al. Depletion of circulating natural type 1 interferon-producing cells in HIV-infected AIDS patients. Blood. 2001; 8(4):906-912.

42. López CB, García-Sastre A, Williams BR, Moran TM. Type I interferon induction pathway, but not released interferon, participates in the maturation of dendritic cells induced by negativestrand RNA viruses. J Infect Dis. 2003;187(7): 1126-1136.

43. Siegal FP, Lopez C, Fitzgerald PA, et al. Opportunistic infections in acquired immune deficiency syndrome result from synergistic defects of both the natural and adaptive components of cellular immunity. J Clin Invest. 1986;78(1):115-123.

44. Donaghy H, Pozniak A, Gazzard B, et al. Loss of blood CD11c + myeloid and CD11c- plasmacytoid dendritic cells in patients with HIV-1 infection correlates with HIV-1 RNA virus load. Blood. 2001;98(8):2574-2576.

45. Almeida M, Cordero M, Almeida J, Orfao A. Different subsets of peripheral blood dendritic cells show distinct phenotypic and functional abnormalities in HIV-1 infection. AIDS. 2005;19(3):261271.

46. Kamga I, Kahi S, Develioglu L, et al. Type I interferon production is profoundly and transiently impaired in primary HIV-1 infection. $J$ Infect Dis. 2005;192(2):303-310.

47. Martinson JA, Montoya CJ, Usuga X, Ronquillo R, Landay AL, Desai SN. Chloroquine modulates HIV-1-induced plasmacytoid dendritic cell alpha interferon: implication for T-cell activation. Antimicrob Agents Chemother. 2010;54(2): 871-881. 